\title{
Causes and 3-year-incidence of blindness in Jing-An District, Shanghai, China 2001-2009
}

Liangcheng $\mathrm{Wu}^{1}$, Xinghuai Sun ${ }^{2^{*}}$, Xingtao Khou $^{2}$ and Chenghai Weng ${ }^{1}$

\begin{abstract}
Background: Registered data can provide valuable information regarding blindness. The purpose of this study was to evaluate the main causes and 3-year incidence of registered blindness in Jing-An district in Shanghai, China.

Methods: Data from the blindness registry (age, gender and cause of visual disability) were collected and analyzed. The prevalence of blindness for 2003, 2007, 2009 and the 3-year incidence of blindness were calculated.

Results: The reported blindness increased significantly from 113.7 per 100,000 in 2003 to 145.8 per 100,000 in 2006 to 165.9 per 100,000 in 2009 ( $P<0.05, P<0.05$, respectively). Age significantly affects prevalence; the odd ratios $(\mathrm{OR})$ were 2.57 in the $30 \mathrm{y}-49 \mathrm{y}$ range $(P<0.001), 7.27$ in the $50 \mathrm{y}-69 \mathrm{y}$ range $(P<0.001)$ and 21.2 in the $\geq 70 \mathrm{y}$ $(\mathrm{P}<0.001)$. The 3-year incidence increased from 32.3 per 100,000 in 2001-2003 to 34.2 per 100,000 in 2004-2006 to 40.8 per 100,000 in 2007-2009. The causes of new blindness registered in 2001-2009 were myopic macular degeneration (19.4\%), followed by glaucoma (17.7\%), age-related macular degeneration (11.8\%), optical nerve atrophy (9.4\%), retinitis pigmentosa (8.6\%), diabetic retinopathy (7.8\%) and corneal opacity (5.8\%).

Conclusions: The 3-year incidence and prevalence of registered blindness increased in the past 9 years. The leading causes of new blindness were myopic macular degeneration, glaucoma and age-related macular degeneration. The pattern of causes has changed little in the past 9 years and is different from other locations in China. The pattern is similar to that of Taiwan, Hongkong, and Western countries.
\end{abstract}

\section{Background}

The World Health Organization (WHO) encourages all countries to monitor the magnitude and causes of visual impairment in order to scrutinize and eliminate avoidable blindness [1]. Registered data can provide valuable information regarding blindness. Blindness registries mainly exist in developed countries and are held by state or partially state funded organizations that provide some kind of assistance to the visually disabled[2]. China is a developing country and cannot provide funds to establish a nationwide networked blindness registry. Also varied socioeconomic conditions affect the development of this project in different regions of China.

Shanghai is the largest metropolis in China and its GDP per capita reached \$10,529 USD in 2008[3]. JingAn district is among the nine downtown districts of Shanghai, where a public welfare system is most

\footnotetext{
* Correspondence: xhsun1962@yahoo.com.cn

Eye and ENT hospital, Shanghai Medical College, Fundan University,

Shanghai, China

Full list of author information is available at the end of the article
}

developed. Jing-An district established a blindness registry in 1992, which is held by the local Disabled Person's Federation (DPF), which is funded by the local government. Although registration is entirely voluntary, it confers significant practical and monetary benefits. We analyzed the data from the Jing-An district DPF with specific objectives including: (1) to identify the causes of registered blindness and to calculate the gender and age-specific prevalence of blindness; (2) to calculate the 3 -year incidence of registered blindness in the most recent 9 years; and (3) to suggest priorities for research and intervention strategies for blindness.

\section{Methods}

This study is based on the blindness data of the Jing-An district DPF. Age, gender and cause of visual disability data were collected and analyzed. The prevalence at the end of years 2003, 2007, 2009 and the 3-year incidence of blindness was calculated. The study was performed in accordance with the Declaration of Helsinki for research involving human subjects. The study met all standards
C Biomed Central

(c) 2011 Wu et al; licensee BioMed Central Ltd. This is an Open Access article distributed under the terms of the Creative Commons Attribution License (http://creativecommons.org/licenses/by/2.0), which permits unrestricted use, distribution, and reproduction in any medium, provided the original work is properly cited. 
for ethical approval in China, and the protocol was approved by the institutional board at the health bureau of Shanghai, China.

The criteria for registering blindness in China are in accordance with the WHO categories of visual impairment, and the category of interest for our study was that the visual impairment was irreversible [4]. Blindness was defined as a best spectacle corrected visual acuity (BSCVA) of less than $3 / 60$ in the better eye, or a corresponding visual field loss to less than 10 degrees in the better eye with best possible correction.

All registered blindness cases need to undergo an assessment of visual impairment. The assessment system has been in place in Jing-An district central hospital from 1992 to the present. In the first 9 years, the causes of blindness were not recorded. From 2001, a comprehensive ocular examination was performed on every applicant including uncorrected visual acuity (UCVA), refraction, BSCVA, ophthalmoscope examination and retinal photography. Visual field tests were performed by a kinetic arctic perimeter (YZ22, 66 Vision Tech. Co., Ltd, China) when visual disability was due to glaucoma, retinitis pigmentosa (RP) and other optic nerve diseases.

The causes of blindness were classified according to the International Classification of Diseases, 10th edition [5]. Myopic macular degeneration (MMD) was considered only in subjects with a refractive error exceeding -6.0 diopters in either eye with one or more of the following ophthalmologic findings: tessellated fundus with yellowish white diffuse or grayish white patchy chorioretinal atrophy, macular hemorrhage or posterior staphyloma [6]. Age-related macular degeneration (AMD) was defined according to the Wisconsin age-related maculopathy grading system [7]. Early AMD was defined by the presence of either soft indistinct drusen or the presence of any type of drusen associated with retinal pigment epithelium depigmentation or increased retinal pigment. Late AMD was defined by the appearance of either exudative macular degeneration or pure geographic atrophy. Glaucoma was defined according to the International Society for Geographical and Epidemiological Ophthalmology classification [8]. Diagnosis of RP was based on night blindness, progressive loss of peripheral visual field, and decreased visual acuity with age, as well as on typical signs observed under fundus examination. The diagnosis of diabetic retinopathy, corneal opacity, and other diseases as causes of blindness followed the ophthalmology practice guidelines edited by the China Academy of Ophthalmology.

Using best judgement, the ophthalmologist attempted to identify the disorder causing the greatest limitation of vision as the cause of blindness. The causes of blindness in both eyes were recorded. When two causes appeared to have an equal contribution to visual impairment for one eye, the primary cause was assigned as the cause of blindness. If cataract was regarded as the main cause of blindness, the patient was referred for surgery and reassessed at least 2 months postoperatively if visual function restored unsatisfactorily.

Statistical analysis was performed using SPSS software version 13 (SPSS, Inc., Chicago, IL). The incidence of blindness caused by some diseases is low and varied in different years in a defined area, so we calculated the 3year incidence of registered blindness per 100,000 in order to reduce the deviation of incidence in different year. And the prevalence of registered blindness per 100,000 were also calculated. Age was grouped as $1 \mathrm{y}-$ 29 y, 30 y -49 y, 50 y -69 y and 70 y or older. Binary logistic regression was used to analyze the factors related to the occurrence of registered blindness. Odds ratios and $95 \%$ confidence intervals were determined to describe the influence of age and gender on the prevalence of visual impairment. A Chi-square test was used to analyze the difference between genders. $\mathrm{P}<0.05$ was considered as statistically significant.

\section{Results}

\section{Prevalence and causes}

The number of people in the blindness registry increased from 378 in 2003 to 458 in 2006 to 514 in 2009. The reported blindness also increased significantly from 114.7 per 100, 000 in 2003 to 145.8 per 100,000 in 2006 to 165.9 per 100,000 in 2009 ( $\mathrm{P}<0.05, \mathrm{P}<0.05$, respectively). The age-specific prevalence and genderspecific prevalence for 2009 are summarized in Table 1.

Table 1 Prevalence of blindness in Jing-An district, Shanghai, China in 2009

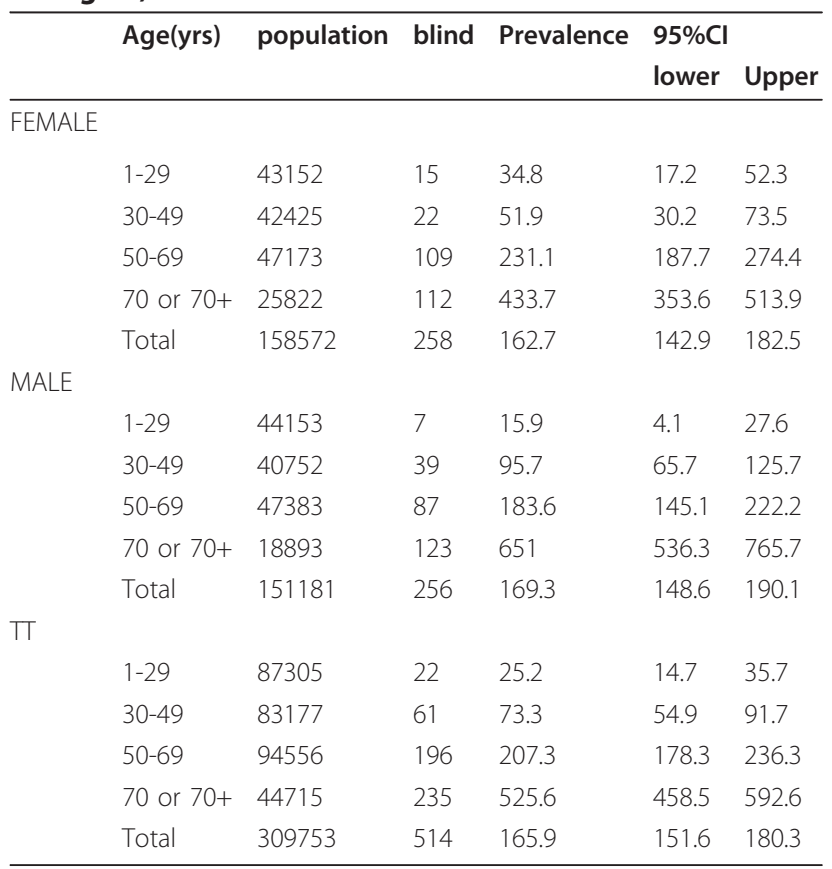


Table 2 Association of registered blindness with gender and age in Jing-an district in 2009

\begin{tabular}{llllll}
\hline & & OR & $\begin{array}{l}\mathbf{9 5 \% C l} \\
\text { lower }\end{array}$ & Upper & P \\
\hline Sex & $\begin{array}{l}\text { male } \\
\text { female }\end{array}$ & 1 & & & \\
age & $1-29$ & 1 & 0.73 & 1.04 & 0.12 \\
& $30-49$ & 2.57 & 2.13 & 3.11 & $<0.001$ \\
& $50-69$ & 7.27 & 5.48 & 9.63 & $<0.001$ \\
& 70 or $70+$ & 21.20 & 13.69 & 32.84 & $<0.001$ \\
\hline
\end{tabular}

$\mathrm{Cl}$ : confidence interval

OR: odds ratio (binary logistic regression)

The association of sex and age with blindness was calculated with a logistic regression model, as shown in Table 2. Gender was not a significant factor, but age significantly affected the prevalence. The odd ratios (OR) were 2.57 in the $30 \mathrm{y}-49$ y group $(\mathrm{P}<0.001), 7.27$ in the $50 \mathrm{y}-69 \mathrm{y}$ group $(\mathrm{P}<0.001)$, and 21.2 in the $70 \mathrm{y}$ or older group $(\mathrm{P}<0.001)$.

The leading causes of blindness that were registered in 2001-2009 are summarized in Table 3. The causes of blindness were MMD (19.4\%), followed by glaucoma (17.7\%), AMD (11.8\%), optical nerve atrophy (9.4\%), RP $(8.6 \%)$, diabetic retinopathy $(7.8 \%)$ and corneal opacity $(5.8 \%)$.

\section{3-year incidence}

The 3-year incidence of registered blindness increased from 32.3 (range 26.0-38.6) per 100,000 in 2001-2003 to 34.2 (range 20.7-40.7) per 100,000 in 2004-2006 to 40.8 (range 40.1-55.5) per 100,000 in 2007-2009 (Table 4). In the blindness registry, retinal detachment was the third cause in 2001-2003, but became the eighth in 2004-2006 and the seventh cause in 2007-2009. Optic nerve atrophy was the fourth cause of blindness in 2001-2003, and became the seventh cause in 2004-2006 and the eighth cause in 2007-2009. However, AMD was the fifth cause in 2001-2003, the third in 2004-2006, and the third in 2007-2009.

\section{Age and new blindness}

The ages of the registered cases of new blindness is summarized in Table 5. The average registered age was $64.19 \pm 15.86 \mathrm{y}$. The average registered age increased from $60.1 \pm 17.3 \mathrm{y}$ in $2001-2003$ to $65.4 \pm 15.2 \mathrm{y}$ in 2004-2006 to 66.1 \pm 14.8 y in 2007-2009 ( $\mathrm{P}<0.05, \mathrm{P}<$ 0.05 , respectively). The main reason for the increased age of new blindness was that there was an increase in the age of the registered blind due to MMD, optic nerve atrophy, corneal opacity and AMD.

\section{Discussion}

To our knowledge, this is the first report on registered blindness in China. Because of the varied socioeconomic levels in China, and the independence of registries in different regions, it is impossible to obtain a complete national dataset, as well as a complete dataset for Shanghai. We therefore analyzed limited data based on the blindness registry in Jing-An district, Shanghai, China.

The number of people in the blindness registry in Jing-An district has increased by 36\% since 2003 and by $13 \%$ since 2007 . In contrast, the population of the district remained stable. The increase in the prevalence and incidence of blindness during 2001-2009 likely represents increased registration rather than increasing levels of disease, considering the short time period involved. Higher life expectancy in the general population in Shanghai may have contributed as well; according to an official publication of the Shanghai Bureau of Statistics, life expectancy in 2001 was $79.7 \mathrm{y}$ and $81.3 \mathrm{y}$ in 2009[3].

Table 3 Causes of new registered blindness in Jing-An district, Shanghai, China in 2001-2009

\begin{tabular}{|c|c|c|c|c|c|c|c|c|c|c|c|c|c|c|c|}
\hline \multirow[b]{2}{*}{ Causes } & \multicolumn{5}{|c|}{ 2001-2003 } & \multicolumn{5}{|c|}{ 2004-2006 } & \multicolumn{5}{|c|}{ 2007-2009 } \\
\hline & cases & eyes & $\%$ & order & $\begin{array}{l}\text { Incidence 1/ } \\
100000\end{array}$ & cases & eyes & $\%$ & order & $\begin{array}{l}\text { Incidence 1/ } \\
100000\end{array}$ & case & eyes & $\%$ & order & $\begin{array}{l}\text { Incidence 1/ } \\
100000\end{array}$ \\
\hline MMD & 15 & 29 & 14.5 & 2 & $4.8(2.4,7.3)$ & 17 & 32 & 15.1 & 1 & $5.5(2.9,8.1)$ & 39 & 74 & 26.1 & 1 & $12.6(8.6,16.5)$ \\
\hline Glaucoma & 19 & 38 & 19.0 & 1 & $6.1(3.4,8.9)$ & 16 & 32 & 15.1 & 1 & $5.2(2.6,7.7)$ & 28 & 53 & 18.7 & 2 & $9.0(5.7,12.4)$ \\
\hline AMD & 13 & 20 & 10.0 & 5 & $4.2(1.9,6.5)$ & 16 & 29 & 13.7 & 3 & $5.2(2.6,7.7)$ & 19 & 33 & 11.6 & 3 & $6.1(3.4,8.9)$ \\
\hline $\mathrm{RP}$ & 6 & 11 & 5.5 & 7 & $1.9(0.4,3.5)$ & 13 & 26 & 12.3 & 4 & $4.2(1.9,6.5)$ & 12 & 23 & 8.1 & 4 & $3.9(1.7,6.1)$ \\
\hline Diabetic & 8 & 16 & 8.0 & 6 & $2.6(0.8,4.4)$ & 8 & 16 & 7.6 & 6 & $2.6(0.8,4.4)$ & 11 & 22 & 7.8 & 5 & $3.6(1.5,5.6)$ \\
\hline $\mathrm{CO}$ & 3 & 4 & 2.0 & 9 & $1.0(0,2.1)$ & 10 & 15 & 7.1 & 7 & $3.2(1.2,5.2)$ & 16 & 21 & 7.4 & 6 & $5.2(2.6,7.7)$ \\
\hline $\mathrm{RD}$ & 15 & 27 & 13.5 & 3 & $4.8(2.4,7.3)$ & 5 & 8 & 3.8 & 8 & $1.6(0.2,3.0)$ & 10 & 16 & 5.6 & 7 & $3.2(1.2,5.2)$ \\
\hline ONA & 13 & 26 & 13.0 & 4 & $4.2(1.9,6.6)$ & 14 & 25 & 11.8 & 5 & $4.5(2.2,6.9)$ & 7 & 14 & 4.9 & 8 & $2.3(0.6,3.9)$ \\
\hline UVITIS & 3 & 6 & 3.0 & 8 & $1.0(0,2.1)$ & 4 & 7 & 3.3 & 9 & $1.3(0,2.6)$ & 6 & 10 & 3.5 & 9 & $1.9(0.4,3.5)$ \\
\hline OTHERS & 17 & 23 & 11.5 & & $5.5(2.9 .8 .1)$ & 12 & 22 & 10.4 & & $3.9(1.7,6.1)$ & 16 & 18 & 6.3 & & $5.2(2.6,7.7)$ \\
\hline Total & 100 & 200 & 100.0 & & $32.3(25.9,38.6)$ & 106 & 212 & 100.0 & & $34.2(27.7,40.7)$ & 142 & 284 & 100.0 & & $45.8(38.3,53.4)$ \\
\hline
\end{tabular}

MMD: myopic macular degeneration; AMD: age-related macular degeneration; ONA: optic nerve atrophy; RP: retinitis pigmentosa; CO: corneal opacity; RD: retinal detachment. 
Table 4 Prevalence and 3-years-incidences of blindness in Jing-An district, Shanghai, China

\begin{tabular}{llll}
\hline & $\mathbf{2 0 0 1 - 2 0 0 3}$ & $\mathbf{2 0 0 4 - 2 0 0 6}$ & $\mathbf{2 0 0 7 - 2 0 0 9}$ \\
\hline Population(10,000) & 33.24 & 30.96 & 30.97 \\
Blind & 378 & 458 & 514 \\
Prevalence rate $(95 \% \mathrm{Cl})(1 / 100,1000)$ & $113.7(102.3-125.2)$ & $147.9(134.4-161.5)$ & $165.9(151.6-180.3)$ \\
New blind & 100 & 106 & 142 \\
3-year-incidence $(95 \% \mathrm{Cl})(1 / 100,1000)$ & $32.3(26.0-38.6)$ & $34.22(27.7-40.7)$ & $47.78(40.1-55.5)$ \\
\hline
\end{tabular}

Currently, the overall prevalence of blindness is $0.17 \%$ for the total population, $0.21 \%$ for ages $50 \mathrm{y}-69 \mathrm{y}$, and $0.53 \%$ for ages $70 \mathrm{y}$ or older. The prevalence in this study is lower than that reported in most studies based on a sample of the population in urban China (Table 6) [6,9-19]. This is possibly due to inclusion of blindness due to cataracts in the studies. A recent study showed the prevalence of blindness was $0.61 \%$ for ages 70 y or older in Shanghai and 29.4\% was due to cataract [17], which is a prevalence rate closer to our results. Another study in Henan province showed that the prevalence of blindness in urban areas was only $0.09 \%$ [18]. To our knowledge, there are no data available on the incidence of blindness in China to compare with this study. It is difficult to compare the incidence and prevalence of blindness with other countries because of different definitions of blindness and difference age distributions. The prevalence of registered blindness was $0.17 \%$ $0.22 \%$ in Ireland (blindness was defined as BSCVA in the better eye of less than $6 / 60)^{2}$ and $0.26 \%-0.32 \%$ in Israel (using WHO criteria) [20]. The incidence of registered blindness was $0.036 \%-0.029 \%$ in Israel (using WHO criteria), $0.02 \%$ in Ireland (using US criteria) and $0.012 \%$ in southern Germany (blindness was defined as BSCVA in the better eye of less than 1/50) [20-22]. In our study, blindness was defined by WHO criteria and cataract was extirpated as the cause of registered blindness. Young babies were also enrolled in this study, which would decrease the prevalence and incidence of blindness.

The leading causes of blindness in the present study were MMD (22.6\%), glaucoma (18.7\%), AMD (11.6\%) and RP (8.1\%). Some studies showed that corneal opacity was also a major cause of blindness in China (shown in Table 5) $[9,12-18]$. In the present study corneal opacity was the eighth cause of blindness. Although the number of cases of corneal opacity increased, along with an increase in the registered age from $43.0 \pm 33.9$ y in $2001-2003$ to $72.8 \pm 11.3$ y in 2007-2009, visual acuity must have been lost in an earlier stage. The reason for this is that infectious keratitis and trachoma have been well controlled in Shanghai. A recent study showed that glaucoma was the eighth cause of blindness and accounted for $4.1 \%$ of blindness in Shanghai, whereas it was the second cause at $18.7 \%$ in the present study [17]. However, no visual field examinations were performed in their study. AMD has increased dramatically as a cause of blindness. It was the fifth cause in 2001-2003, while it became the third cause in 2007-2008. The pattern of causes of blindness was similar to that in Taiwan, Hongkong, and Western countries [6,11,20-22]. Glaucoma and AMD have also become the leading causes of blindness in the Jing-An district of Shanghai.

Table 5 Registered age of new blindness in Jing-An district, Shanghai, China

\begin{tabular}{|c|c|c|c|c|}
\hline & 2001-2009 & 2001-2003 & 2004-2006 & 2007-2009 \\
\hline & Mean \pm 1SD & Mean $\pm 1 S D$ & Mean \pm 1SD & Mean $\pm 1 S D$ \\
\hline$\overline{\text { Glaucoma }}$ & $67.30 \pm 14.61$ & $65.89 \pm 14.01$ & $67.94 \pm 16.23$ & $67.89 \pm 14.52$ \\
\hline Diabetic & $63.00 \pm 13.79$ & $63.38 \pm 13.73$ & $58.00 \pm 14.14$ & $63.64 \pm 14.92$ \\
\hline MMD & $61.32 \pm 12.22$ & $54.60 \pm 16.61$ & $61.12 \pm 11.36$ & $64.00 \pm 9.68^{*}$ \\
\hline $\mathrm{RP}$ & $57.29 \pm 13.83$ & $58.00 \pm 13.28$ & $59.15 \pm 10.16$ & $54.92 \pm 17.83$ \\
\hline AMD & $75.31 \pm 9.42$ & $71.00 \pm 8.98$ & $77.70 \pm 9.28^{*}$ & $75.74 \pm 9.31$ \\
\hline ONA & $59.25 \pm 17.43$ & $53.23 \pm 19.74$ & $66.69 \pm 12.24^{*}$ & $53.43 \pm 18.82$ \\
\hline $\mathrm{CO}$ & $67.52 \pm 16.55$ & $43.00 \pm 33.87$ & $66.40 \pm 11.50^{*}$ & $72.81 \pm 11.33^{*}$ \\
\hline $\mathrm{RD}$ & $61.97 \pm 13.78$ & $57.47 \pm 15.58$ & $68.80 \pm 8.81$ & $65.30 \pm 11.28$ \\
\hline UVITIS & $62.77 \pm 14.93$ & $60.33 \pm 14.15$ & $59.25 \pm 11.95$ & $66.33 \pm 18.45$ \\
\hline OTHERS & $59.93 \pm 23.18$ & $58.44 \pm 21.51$ & $54.18 \pm 27.03$ & $65.73 \pm 22.16$ \\
\hline Total & $64.19 \pm 15.86$ & $60.10 \pm 17.29$ & $65.43 \pm 15.24^{*}$ & $66.12 \pm 14.82^{*}$ \\
\hline
\end{tabular}

MMD: myopic macular degeneration; AMD: age-related macular degeneration ONA: optic nerve atrophy; RP: retinitis pigmentosa; CO: corneal opacity; RD: retinal detachment.

*:P $<0.05$ compared to in 2001-2003 
Table 6 Prevalence of blindness and its causes reported from population based studies in china

\begin{tabular}{|c|c|c|c|}
\hline Country & Age(yrs) & Prevalence & Main causes \\
\hline $\begin{array}{l}\text { Beijing, China } \\
\text { (Xu L et al.2006) }\end{array}$ & $>=40$ & $0.3 \%$ & Cataract(38.5\%); Cornea opacity (15.4\%);Myopic macular degeneration(7.7\%); Glaucoma(7.7\%) \\
\hline $\begin{array}{l}\text { Handan china } \\
\text { (Liang YB et al. 2008) }\end{array}$ & $>=30$ & $0.5 \%$ & $\begin{array}{l}\text { Cataract (36.6\%);Myopic macular degeneration (19.5\%) } \\
\text { Glaucoma(7.3\%);Cornea opacity(7.3\%) }\end{array}$ \\
\hline $\begin{array}{l}\text { Taiwan, China } \\
\text { (Hsu WM, et al. 2004) }\end{array}$ & $>=65$ & $0.59 \%$ & $\begin{array}{l}\text { Cataract (41.7\%);Myopic macular degeneration (12.5\%) } \\
\operatorname{AMD}(10.4 \%)\end{array}$ \\
\hline $\begin{array}{l}\text { Hongkong, China } \\
\text { (Michon JJ, et al. 2002) }\end{array}$ & $>=60$ & $1.8 \%$ & $\begin{array}{l}\text { Cataract (51.7\%);Macular degeneration (27.1\%) } \\
\text { Glaucoma(7.1\%) }\end{array}$ \\
\hline $\begin{array}{l}\text { Hebei, China } \\
\text { (Song XJ.1992) }\end{array}$ & & $\begin{array}{l}0.19 \% \\
\text { in urban } \\
\text { areas }\end{array}$ & $\begin{array}{l}\text { Cataract(32.3\%);trachoma complications(13.4\%) } \\
\text { corneal disease(13.06\%); glaucoma(9.97\%) }\end{array}$ \\
\hline $\begin{array}{l}\text { Shanxi, China } \\
\text { (Zhang JX.1990) }\end{array}$ & & $\begin{array}{l}0.18 \% \\
\text { in cities }\end{array}$ & Cataract (29.7\%) \\
\hline $\begin{array}{l}\text { Shangdong, china } \\
\text { (Yu XM.1992) }\end{array}$ & & $0.34 \%$ & Cataract, corneal diseases and glaucoma in urban areas \\
\hline $\begin{array}{l}\text { China } \\
\text { (Zhang SY.1992) }\end{array}$ & & $0.43 \%$ & $\begin{array}{l}\text { Cataract(41.06\%);Corneal disease(15,38\%) } \\
\text { Trachoma (10.4\%);Glaucoma (8.8\%) }\end{array}$ \\
\hline $\begin{array}{l}\text { Chongqing, china } \\
\text { (Liu S, et al. 2007) }\end{array}$ & $>50$ & $1.8 \%$ & $\begin{array}{l}\text { Cataract }(17.9 \%) ; \text { Retinal diseases }(20.7 \%) \text {; refraction error }(15.4 \%) \text {; } \\
\text { cornea disease }(11.6 \%) \text {; glaucoma }(13.4 \%)\end{array}$ \\
\hline $\begin{array}{l}\text { Shanghai } \\
\text { (Huang XB, et al. 2009) }\end{array}$ & & $\begin{array}{l}0.95 \% \\
\text { in } 60-79 \text { yrs } \\
0.68 \% \\
\text { in } 70-79 \text { yrs } \\
0.40 \% y r s \\
\text { in } 80 \text { yrs or } \\
\text { older }\end{array}$ & $\begin{array}{l}\text { Macular degeneration(28.57\%);Cataract(27.27\%); Corneal opacity (6.49\%); } \\
\text { Retinal detachment (5.84\%); Optical nerve atrophy (5.19\%); Retinitis pigmentosa (5.19\%) }\end{array}$ \\
\hline $\begin{array}{l}\text { Henan } \\
\text { (Li Y et al.2009) }\end{array}$ & & $\begin{array}{l}0.09 \% \\
\text { in urban }\end{array}$ & no noted \\
\hline $\begin{array}{l}\text { Hubei } \\
\text { (Chen W et al. 2009) }\end{array}$ & & $\begin{array}{l}0.33 \% \\
\text { in urban }\end{array}$ & $\begin{array}{l}\text { Cataract (54.55\%);Glaucoma(10.22\%); Congenital abnormal (8.41\%);Corneal disease(7.48\%); } \\
\text { Retinal and choroidal disease (6.54\%) }\end{array}$ \\
\hline
\end{tabular}

The analysis shows the importance of glaucoma as the leading cause of blindness in China today. Most patients with glaucoma can maintain sufficient visual acuity if effective treatment is given at an early stage, especially for primary angle-closure glaucoma (PACG), which is major category of glaucoma in China. The study showed that $92.86 \%$ of blindness due to glaucoma occurred at 51 y or older. We therefore suggest that local health bureaus should conduct glaucoma screening for those aged 51 y or older to diagnose glaucoma at an early stage.

AMD and MMD are the chief causes leading to blindness. Unfortunately, for most people with AMD, vision loss can neither be prevented nor adequately reversed. There is clearly a need for further research on the causes and risk factors of AMD. Persons with MMD will also benefit from the research. Controlling the development of high myopia is impending. Research on the mechanisms of myopia progression is necessary to decrease the vision impairment burden of students.

This study is based on registered data for a defined geographic area. We acknowledge there are some limitations in our study. We had to rely on the limited information from the CDPF, and the causes of blindness registered before 2001 were not recorded. The increase in the prevalence and incidence of blindness likely represents increased registration rather than increasing levels of disease. In this study, the cause of blindness was recorded for each eye, which would increase the proportion of disorders with a bilateral tendency such as AMD, MMD and glaucoma as the cause of blindness. It would be better to record the causes by case. The efficacy of the registration system is not certain. Previous studies in other countries found that only $45 \%-60 \%$ of eligible patients were registered [23]. It is therefore necessary to make a dedicated effort to evaluate the efficacy of the registry system in China.

\section{Conclusions}

The 3-year incidence and reported blind increased in the past 9 years. The leading causes of new cases of blindness that were registered were MMD, glaucoma and AMD. The pattern of causes has changed little in the past 9 years, is different from other locations in China, and is similar to patterns in Taiwan, Hongkong and Western countries. 


\section{Abbreviations}

WHO: The World Health Organization; DPF: Disable Person's Federation: BSCVA: best spectacle corrected visual acuity; UCVA: uncorrected visual acuity; MMD: Myopic macular degeneration; AMD: Age-related macular degeneration; RP: Diagnosis of retinitis pigmentosa.

\section{Acknowledgements}

This research was supported by Foundation of Health Science Research of the Health Bureau of Shanghai, China (No.: 2008-161), Shi-Bai-Qian Plans of Jing-An district health bureau, Shanghai, China (2010020103), and the Funds for International Cooperation and Exchange of the National Natural Science Foundation of China (Grant No. 81020108017).

\section{Author details}

${ }^{1}$ Jing-An District Central Hospital, Shanghai, China. ${ }^{2}$ Eye and ENT hospital, Shanghai Medical College, Fundan University, Shanghai, China.

\section{Authors' contributions}

LW carried out the data collection, performed data analysis and drafted the manuscript. XS participated in the design of the study. XZ and CW participated in the study design and coordination and helped to draft the manuscript. All authors read and approved the final manuscript.

\section{Competing interests}

The authors declare that they have no competing interests.

Received: 10 December 2010 Accepted: 5 May 2011 Published: 5 May 2011

\section{References}

1. Resnikoff S, Pascolini D, Kocur I, Pararajasegaram R, Pokharel GP, Mariotti SP: Global data on visual impairment in the year 2002. Bull World Health Org 2004, 82:844-51.

2. Munier A, Gunning T, Kenny D, O'Keefe M: Causes of blindness in the adult population of the Republic of Ireland. Br J Ophthalmol 1998, 82:630.

3. Shanghai Statistical Yearbook: 2009 [http://www.stats-sh.gov.cn].

4. World Health Organisation: International classification of impairments, disabilities and handicaps. Geneva: WHO; 1980, 79-85.

5. World Health Organization: Diseases of the eye and adnexa. International statistical classification of diseases and related health problems: ICD-10, tenth revision. Geneva: World Health Organization; 2004:1:426-428.

6. Hsu WM, Cheng CY, Liu JH, Tsai SY, Chou P: Prevalence and causes of visual impairment in an elderly Chinese population in Taiwan: the Shihpai Eye Study. Ophthalmology 2004, 111:62-9.

7. Klein R, Davis MD, Magli YL, Segal P, Klein BE, Hubbard L: The Wisconsin age-related maculopathy grading system. Ophthalmology 1991, 98:1128-34.

8. Foster PJ, Buhrmann R, Quigley HA, Johnson GJ: The definition and classification of glaucoma in prevalence surveys. $\mathrm{Br} J$ Ophthalmol 2002, 86:238-42.

9. Xu L, Wang Y, Li Y, Wang Y, Cui T, Li J, Jonas JB: Causes of blindness and visual impairment in urban and rural areas in Beijing: the Beijing Eye Study. Ophthalmology 2006, 113:1134-113.

10. Liang YB, Friedman DS, Wong TY: Prevalence and causes of low vision and blindness in a rural chinese adult population: the Handan Eye Study. Ophthalmology 2008, 115:1965-72.

11. Michon JJ, Lau J, Chan WS, Ellwein LB: Prevalence of visual impairment, blindness, and cataract surgery in the Hong Kong elderly. $\mathrm{Br} J$ Ophthalmol 2002, 86:133-9.

12. Song XJ: An epidemiological survey of blindness and low vision in Hebei Province. Zhonghua Yan Ke Za Zhi 1992, 28:105-7.

13. Zhang JX: A survey of blindness and low vision in Shanxi Province. Zhonghua Yan Ke Za Zhi 1990, 26:39-42.

14. Yu XM: An epidemiological survey of blindness and low vision in Shandong Province. Zhonghua Yan Ke Za Zhi 1992, 28:363-6.

15. Zhang SY: The 1987 National Epidemiological Survey of Blindness and Low Vision in China. Zhonghua Yan Ke Za Zhi 1992, 28:260-4.

16. Liu S, Chen L, Ouyang L, Peng Q: The survey of prevalence of blindness in Nan'an District of Chongqing. Zhonghua Yan Ke Za Zhi 2007, 43:722-5.
17. Huang $X B$, Zou $H D$, Wang $N$ : A prevalence survey of blindness and visual impairment in adults aged equal or more than 60 years in Beixinjing blocks of Shanghai, China. Zhonghua Yan Ke Za Zhi 2009, 45:786-92.

18. Li YY, Zhu Y, Li ZG, Chen P, Yan SJ: A cross-sectional study on the visual disability of the residents in 2006 in Henan province, China. Zhonghua Yan Ke Za Zhi 2009, 45:781-5.

19. Chen W, Liu J, Lu YH, Hu YZ, Lu YX, You CJ: A cross-sectional study on the prevalence of visual impairment in 2006 in Hubei province, China. Zhonghua Yan Ke Za Zhi 2009, 45:776-80.

20. Avisar R, Friling R, Snir M, Avisar I, Weinberger D: Estimation of prevalence and incidence rates and causes of blindness in Israel, 1998-2003. Isr Med Assoc J 2006, 8:880-1.

21. Kelliher C, Kenny D, O'Brien C: Trends in blind registration in the adult population of the Republic of Ireland 1996-2003. Br J Ophthalmol 2006, 90:367-71.

22. Trautner C, Haastert B, Richter B, Berger M, Giani G: Incidence of blindness in southern Germany due to glaucoma and degenerative conditions. Invest Ophthalmol Vis Sci 2003, 44:1031-1034.

23. Bunc C, Evans J, Frase S, Wormald R: BD8 certification of visually impaired people. Br J Ophthalmol 1998, 82:72-76.

24. Barry RJ, Murray PI: Unregistered visual impairment: is registration a failing system? Br J Ophthalmol 2005, 89:995-8.

\section{Pre-publication history}

The pre-publication history for this paper can be accessed here: http://www.biomedcentral.com/1471-2415/11/10/prepub

doi:10.1186/1471-2415-11-10

Cite this article as: Wu et al: Causes and 3-year-incidence of blindness in Jing-An District, Shanghai, China 2001-2009. BMC Ophthalmology 2011 11:10.

\section{Submit your next manuscript to BioMed Central and take full advantage of:}

- Convenient online submission

- Thorough peer review

- No space constraints or color figure charges

- Immediate publication on acceptance

- Inclusion in PubMed, CAS, Scopus and Google Scholar

- Research which is freely available for redistribution

Submit your manuscript at www.biomedcentral.com/submit
Ciomed Central 